\title{
CONTRIBUIÇÕES DA FILOSOFIA DE HENRI BERGSON PARA A EDUCAÇÃO
}

\author{
Luka de Carvalho Gusmão ${ }^{1}$
}

\section{Resumo}

O objetivo do trabalho é promover uma primeira investigação em torno do pensamento de Henri Bergson e inferir suas contribuições para a educação. Analiso os conceitos de duração e intuição, e concluo que eles permitem adotar uma postura de respeito às diferenças, de reconstrução permanente do currículo, estímulo à criatividade, reflexão e livre iniciativa de professores e alunos.

Palavras-chave: Henri Bergson. Duração. Intuição. Educação.

\section{Resumen}

El objetivo del trabajo es promover una primera investigación acerca del pensamiento de Henri Bergson e inferir sus contribuciones para la educación. Hago un análisis de los conceptos de "duración" y "intuición", y llego a la conclusión que ellos permiten la adopción de una postura de respeto a las diferencias, de reconstrucción permanente del currículo, empuje a la creatividad, reflexión e libre iniciativa de maestros y alumnos.

Palabras clave: Henri Bergson. Duración. Intuición. Educación.

\section{Introdução}

O presente artigo é uma adaptação do trabalho de conclusão de curso que realizei para obtenção do título de Bacharelado em Educação. Ele contém o resultado das primeiras pesquisas que levei a efeito sobre as possíveis relações entre a filosofia de Henri Bergson e a Educação.

Henri Bergson desenvolveu seu pensamento em torno dos conceitos de duração e intuição. O tempo da vida, chamado por ele de duração, é considerado a substância mesma da realidade, e a intuição, o meio mais adequado de se conhecê-la. Santos Pinto (2010) afirma que se de um lado a duração se constituiu o objeto da reflexão bergsoniana, o campo noemático sobre o qual se desdobrou seu pensamento, de outro, a intuição, na condição de meio

\footnotetext{
${ }^{1}$ Mestrando em Educação, Universidade Federal de Juiz de Fora, lukagusmao87@yahoo.com.br

GUSMÃO, Luka de Carvalho. Contribuições da filosofia de Henri Bergson para a educação. Revista Sul-Americana de Filosofia e Educação. Número 25: nov/2015 abril/2016, p. 134-152.
} 
mais apropriado de conhecimento, se tornou, ao longo de seu percurso intelectual, um método rigoroso de conhecimento.

Ora, se a realidade vivenciada por nós é duração e está constantemente se construindo, se o meio apropriado para conhecê-la é a intuição; e se por outro lado a realidade vivenciada por nós na escola - e fora dela - é, em princípio, essa descrita por Bergson, se para a conhecermos de fato - como propõe a escola pela natureza de seu trabalho - é preciso que recorramos a outros meios além dos métodos convencionais da inteligência, perguntamos: como o pensamento de Bergson pode nos ajudar a repensar a educação? Quais mudanças educacionais nós podemos conceber a partir de sua filosofia? Dissemos acima que este trabalho constitui uma iniciação acadêmica no estudo da obra de Henri Bergson, razão pela qual não alimentemos a ambição de esgotar de uma só vez todas as possibilidades de responder a essas questões, lembrando ainda que elas poderão ser desenvolvidas em trabalhos posteriores.

Por hora, utilizaremos como fonte para nosso estudo alguns textos nos quais Bergson tentou apresentar de modo conciso seu pensamento acerca da duração $e$ intuição, quais sejam: Introdução (Primeira parte) e Introdução (Segunda parte) de O Pensamento e o Movente; A Intuição Filosófica; e Introdução à Metafísica. Procuraremos restringir nossas reflexões ao âmbito do material pesquisado atendonosaos dados que os próprios textos nos fornecem, sem a pretensão de dar conta de todas as contribuições da extensa e profunda obra de Bergson para o campo da educação.

\section{A vida e a obra de Henri Louis Bergson}

Em 18 de outubro de 1859, nasceu na França, Henri Louis Bergson, um pensador contemporâneo que contribuiu significativamente para a filosofia e a ciência de nossa época.

No ano de 1878, ingressou na Escola Normal Superior no setor de Letras, mostrando também grande interesse pela Filosofia, sendo designado, três anos mais tarde, para o cargo de professor no Liceu de Angers e dois 
anos depois em Clermont-Ferrand. Pessanha (1979) informa que nesta época Bergson publicou Trechos de Lucrécio aonde abordou tanto o tratamento que devemos dar ao estudo da História da Filosofia quanto uma crítica ao determinismo.

No ano de 1888 defendeu suas duas teses de doutorado, sendo que a primeira continha um estudo sobre a concepção de lugar em Aristóteles e a segunda, chamada Ensaio sobre os dados imediatos da consciência, o desenvolvimento da noção de duração em relação à vida psicológica.

O pensador francês não interrompeu sua produção filosófica após o término de sua primeira obra e, mesmo trabalhando intensamente como professor, publicou, no ano de 1897, Matéria e memória - Ensaio sobre a relação entre corpo e espírito, aonde, através do estudo da relação entre espírito e matéria, ampliou suas reflexões acerca da realidade da duração.

Pessanha (1979) nos informa que, nos primeiros anos do século XX, Bergson conheceu o respeitado psicólogo e filósofo norte-americano Willian James, com quem desenvolveu, apesar de certas diferenças filosóficas, uma sólida amizade, que ficou expressa nas cartas com as quais se correspondiam. Neste período, mais precisamente no ano de 1907, Bergson publicou a obra de maior destaque em seu pensamento: A Evolução Criadora.

Em 1919 trouxe a público o livro A Energia Espiritual, obra composta por escritos cujos temas perpassaram a consciência e a vida, a relação entre corpo e alma, o sonho, a relação entre cérebro e pensamento. Logo em seguida, em 1922, apresentou-nos Duração e Simultaneidade, obra na qual revela as reflexões que realizou acerca das teorias da relatividade e dos tempos múltiplos.

Apesar do agravamento das dificuldades de saúde que enfrentava, o pensador francês continuou seu trabalho. Em 1932, publicou As Duas Fontes da Moral e da Religião, livro que, de acordo com Santos Pinto (2010) e Pessanha (1979), desdobrou sua concepção de duração em relação ao desenvolvimento moral e religioso. Vieillard-Baron (2007) nos informa ainda que tal obra levantou grande polêmica, que se fazia através de críticas distorcidas ao seu pensamento. Dois anos mais tarde Bergson publicou O Pensamento e o Movente, coletânea 
de conferências e textos que, de certa forma, sintetizavam sua filosofia. Estes dois últimos livros confirmaram a admiração em torno de seu pensamento, mas, efetivamente, seu prestígio já havia sido consolidado desde 1928, ano em que ganhou o prêmio Nobel de Literatura.

Bergson morreu no ano de 1941. Pessanha (1979) afirma que o pensador francês, embora de origem judia, manifestou aproximação crescente ao cristianismo no fim de sua vida, mas não se converteu, pois não queria abandonar seu povo no período da perseguição nazista.

No Brasil, o pensamento de Bergson ganhou visibilidade e espaço apenas no fim do século XX, graças, sobretudo, aos trabalhos de Bento Prado Junior e Franklin Leopoldo e Silva. A formação e produção de Prado Junior, no que tange o pensamento de Bergson, se concretizaram graças à sua permanência na França no período de 1961 a 1963, quando teve acesso às notas de um curso sobre o primeiro capítulo de Matéria e memória. Neste contexto Prado Junior iniciou a elaboração da obra Presença e Campo Transcendental Consciência e negatividade na filosofia de Bergson, que teve grande repercussão no meio filosófico. Contudo, embora tenha sido redigido na década de 1960, a obra só foi publicada no Brasil em 1989, em razão do regime da ditadura militar. Mas foi através dela que muitos pesquisadores iniciaram o estudo do pensamento de Bergson a partir de 1990.

Franklin Leopoldo e Silva - outro filósofo brasileiro responsável pela difusão do pensamento bergsoniano no país - publicou na década de 1990 sua livre-docência na Universidade de São Paulo, intitulada Bergson - Intuição e Discurso Filosófico. Morato Pinto, Borba e Kohan (2007, p. 14) acreditam que esta obra apresenta "pistas para entender a proposta de uma linguagem conveniente à filosofia" e explicita "a necessidade do exame detalhado das teorias tradicionais do tempo para a apreensão do sentido mais fundamental do método da intuição e sua relação com o discurso".

Os alunos orientados por Franklin Leopoldo e Silva e Bento Prado Junior constituíram uma rede de pesquisadores do pensamento de Bergson, Sartre e Merleau-Ponty. Essa rede se institucionalizou no grupo de trabalho Filosofia 
Francesa Contemporânea da Associação Nacional de Pós-graduação em Filosofia (ANPOF) e no grupo de pesquisa com o mesmo nome, vinculado ao Conselho Nacional de Desenvolvimento Científico e Tecnológico (CNPq).

\section{A duração e a intuição em Bergson}

Complementando o que escrevemos acima, no ano de 1878, Henri Louis Bergson ingressou na Escola Normal Superior onde se graduou em Filosofia. Nesta época, o pensador francês pretendia aprofundar-se no campo da Filosofia da Ciência, contudo, na busca de uma doutrina filosófica que pudesse sustentar seu pensamento, Bergson (1979a) concluiu após alguns estudos, que as teorias tradicionais apresentavam muitas abstrações que, por sua vez, não representavam a realidade de modo preciso. Passou então a considerar que a Filosofia deveria, assim como a Ciência, apoiar-se em fatos.

Deste modo, Bergson (1979a) iniciou o estudo da doutrina de Herbert Spencer, pois percebeu que ela tinha o objetivo de se moldar sobre dados reais, mas considerou em seguida que ela estava ainda incipiente e por este motivo propôs-se completá-la e consolidá-la. Porém, ao chegar à ideia de tempo que lhe era subjacente, viu que suas consequências na compreensão da evolução da vida (aspecto central da obra de Spencer) não correspondiam ao progresso real experimentado por um ser vivo. Bergson (1979d; 1979a) acreditava que dessa realidade temporal em constante progresso teríamos a experiência pessoal em nossa própria consciência, pela qual poderíamos, em última análise, iniciar o estudo da metafísica, campo no qual a partir de então ingressou. Fora conduzido ao estudo do tempo (o qual denominou de duração) e, examinando a história da Filosofia e da Ciência, Bergson (1979a) constatou que a duração não fora anteriormente aprofundada pelos pensadores, justamente pelo fato de se ter confundido as noções de tempo e espaço. Sendo este último, até certo ponto, passível de medição, segmentação e recomposição conceitual rigorosa, julgou-se que o primeiro também o era, formando-se a noção de tempo espacializado ou, como o próprio Bergson diz (1979a), o conceito de tempo das matemáticas. 
Com o propósito de compreender mais a fundo as causas desta confusão, Bergson (1979a) deu início ao estudo da estrutura do entendimento humano e percebeu que ele atuava normalmente desconsiderando a duração real. Para Bergson (1979a), a operação habitual da inteligência consistia em recortar na totalidade do real aquilo que pretendia conhecer, isolar este recorte do restante e analisá-lo. Consequentemente, ao utilizarmos esta operação de nossa inteligência para conhecermos o movimento de um modo geral, reteríamos dele apenas uma série de posições que recortaríamos e estudaríamos separadamente. Se, no entanto, buscássemos conhecer o movimento sem fragmentá-lo, tal como se apresenta na vida, ele se revelaria como uma duração, uma continuidade indivisível em ininterrupta construção (BERGSON, 1979d; 1979a). Não se poderia, deste modo, confundir-se a representação intelectual que criamos do tempo com o tempo em si, a representação intelectual do movimento com o movimento mesmo (BERGSON, 1979a).

Com o conceito de mudança estaríamos cometendo o mesmo tipo de erro quando buscássemos representá-lo por meio de nossa inteligência, fragmentando em partes a duração e a expressando em função de cada um dos estágios pelos quais ela supostamente passou (BERGSON, 1979a), como se a mudança fosse uma sucessão de estados prontos e pré- determinados e não uma criação imprevisível. O tempo que passa seria um fluxo contínuo de novidades, não um ciclo justaposto de acontecimentos interligados em uma cadeia mecanicista de causa e efeito, pois tal cadeia poderia nos dar a ideia de que o futuro está pronto e dado ao presente.

Bergson (1979a) afirmou que muitos dos problemas e impasses criados na Filosofia e na Ciência ocorreram em função desta representação intelectual da realidade. Considerava que tais problemas nasceram no dia em que Zenão de Eléia assinalou a impossibilidade de tomarmos a mudança e o movimento como base para representarmos a essência das coisas. Bergson (1979d; 1979a) afirmou que desde então a Filosofia foi levada a conhecer o real abstraindo o movimento e a mudança, objetivando o estático, o imutável, o abstrato e o universal, propondo, em contraposição, outra visão acerca da realidade, representada por sua vez pelas 
noções de duração, movimento, mudança, diversidade, criação e novidade. A duração nos traria a noção de que o movimento da vida é uma constante criação de realidades novas e imprevisíveis, que estaríamos constantemente nos esforçando para apreender.

Neste sentido, dizia Bergson (1979a) que se observássemos a vida sobre a ótica da duração - sendo esta a liberdade em si mesma - veríamos que ela cresce e evolui interiormente e cria a novidade na medida em que se relaciona com o Universo do qual faz parte. Para Bergson (1979a) também poderíamos aplicar este princípio da duração na compreensão da evolução da sociedade, da política e das artes literárias que foram e são fruto de um processo histórico criativo que não se podia e não se pode prever e determinar com absoluta certeza. Para ele, seria possível estudarmos o passado a fim de perceber como se desenrolaram os fatos que culminaram na criação de certas circunstâncias, mas no movimento mesmo em que se davam eram de fato criações e novidades, assim como o futuro da nossa sociedade será fruto de novas escolhas criadas com base no presente de múltiplas possibilidades.

A criação do novo, a mudança, a evolução seriam frutos do movimento, do próprio tempo. A experiência e a percepção humana, por sua vez, captariam este movimento e proporcionariam, ao lado da inteligência, o desenvolvimento do aprendizado, por conseguinte, a evolução. Bergson (1979d; 1979b) combateu a ideia de que haveria uma incapacidade de nossa percepção para conhecer a duração, ou seja, esta realidade em mudança. Para ele esta faculdade seria plena de significado e, por conseguinte, válida. As verdades eternas, em tese, preexistentes à percepção e à razão na condição de ideias prontas e acabadas, com efeito, não seriam para o sujeito que as concebeu, mais do que produto da intuição que tivera da duração, portanto, novidades imprevisíveis até terem sido criadas pela razão humana. Para ele a coisa e a ideia da coisa, sua realidade e sua possibilidade são criadas ao mesmo tempo (BERGSON, 1979a). Neste sentido, teoria da vida e teoria do conhecimento estariam interligados. 
Assim Bergson (1979a) decidiu estudar o problema da liberdade em sua concretude no campo da consciência humana a fim de encontrar a duração e testar seu método de investigação filosófica, que por sua vez pretendia entrar em contato direto com o imediato, com o objeto em si. A partir deste concluiu ser necessário que a Psicologia abandonasse $\mathrm{o}$ associacionismo $e$ a metafísica abandonasse as limitações que Kant havia the colocado com suas restrições à capacidade cognitiva da percepção e da razão humanas (BERGSON, 1979a; 1979b). A crítica de Kant à metafísica havia se apoiado em uma concepção transcendental da realidade espiritual, para a qual nos faltaria as faculdades necessárias (BERGSON, 1979c).

Bergson (1979b) utilizou a intuição como método filosófico para o desenvolvimento de sua obra, mas não no sentido que fora empregado por outros expoentes da História da Filosofia. Segundo o pensador francês, a bem dizer, a intuição se achava na base do pensamento da maior parte dos filósofos (BERGSON, 1979c) e, embora nunca tivesse sido praticada de maneira metódica, fora a responsável pelos grandes avanços da Ciência ao longo dos tempos (BERGSON, 1979d). Muitos foram aqueles que a haviam concebido como um contato direto do espírito humano com a realidade vivida, mas com vistas à apreensão de sua essência imutável, de uma verdade eterna, o que Bergson, em última instância, criticava (BERGSON, 1979b). Bergson (1979b) acreditava que o método intuitivo seria um procedimento de pesquisa que deveria ser utilizado pela metafísica para conhecer a dinamicidade, a duração da vida, com base em fatos, através da experiência concreta do espírito com o objeto. Ele acreditava que este método seria capaz de colocar o pensador em contato direto com a realidade na qual vive - da qual, aliás, é parte -, que percebe e interiormente sente.

Bergson (1979b) asseverou, aliás, que esta realidade, de um modo geral, possuía um elemento espiritual, e concluiu, assim como fora dito anteriormente, que sua essência era durar, comportando-se de modo análogo à consciência humana, ou seja, se apresentando de modo, até certo ponto, imprevisivel, deixando transparecer que possuiria liberdade. Ele concluiu enfim, que a intuição seria capaz de captar em profundidade esta duração que 
perpassaria substancialmente todas as coisas. Considerava, no entanto, que, dado os graus de consciência de cada ser, esta duração seria intuída e exprimida em bases mais ou menos diferenciadas, o que nos levaria à produção de diversas filosofias (BERGSON, 1979b). Não haveria, por conseguinte, uma fórmula conceitual única que definiria o método intuitivo, embora ele esteja fundamentado em certos princípios.

Aquele que, no entanto, quisesse compreender tal método precisaria colocar-se no movimento temporal da realidade, ampliando o grau de sua percepção e consciência acerca daquilo que desejaria conhecer. $\mathrm{O}$ método intuitivo de acordo com Bergson (1979 b) se fundamentaria primordialmente neste aspecto. A intuição ao colocar o pensador em meio ao devir, transformá-loia em aprendiz frente a uma realidade que é, a cada momento, nova, a qual lhe caberia, em última instância, experimentar e descobrir. A este respeito Bergson (1979b) esclarecia que para se chegar a conhecer algo por meio de seu método seria preciso de fato predispor-se a aprender pacientemente com as acuradas observações que se poderia fazer. Isto, aliás, se nos afiguraria como trabalho um tanto árduo, mas original e criativo.

Bergson (1979d; 1979b) acreditava que esse método era tão preciso quanto o que a Ciência utilizava em suas pesquisas. Ele considerava que se a inteligência em sua estrutura estaria apta para o conhecimento daquilo que, até certo ponto, seria estático e imutável, ou seja, a matéria, o método intuitivo estaria apto para apreender o espírito, ou seja, a duração, o movimento, a mudança, a singularidade da criação daquilo que de modo algum se repete. Se, em última análise, utilizaríamos o método analítico da inteligência para separar em partes a realidade material que nos circunda e estudar suas propriedades não poderíamos fazer o mesmo, por exemplo, com a alma humana que não seria em si senão esse movimento qualitativo e contínuo de mudança e novidade. Como de fato, poder-se-ia representar de modo completo, através de quadros estáticos, aquilo que é mudança de qualidade contínua? A intuição seria, portanto, o meio mais próprio para se chegar a conhecer esta realidade em constante construção. O erro da ciência e da metafísica, conforme esclareceu Bergson 
(1979d), consistiu em não estabelecer diferenças entre estes dois modos distintos embora complementares - de atividade do pensamento humano. Fora o desconhecimento desta distinção que fez Kant acreditar que a intuição em toda sua extensão e profundidade fosse impossível de ser praticada e que a inteligência analítica seria o único meio possível de conhecimento da verdade, conclusão que o levou a afirmar a inviabilidade de se obter conhecimento verdadeiro na metafísica (BERGSON, 1979d).

A intuição, entretanto, não descartaria o valor da inteligência e dos conceitos por ela gerados, mas sim apresentaria seus limites em relação à capacidade de tocar a duração (1979d). Asseverava Bergson (1979b) que a gama de conhecimentos armazenados na linguagem pela tradição científica e filosófica não seriam mais do que pontos de partida para aquele que desejasse conhecer por si mesmo o sentido mais profundo do objeto pesquisado. O filósofo, assim como o cientista, deveria ater-se à representação que de modo mais preciso se adequasse àquilo que a experiência concreta com o objeto revelasse, ainda que para isso fosse necessário discordar do que fora ensinado na tradição e criar algo novo $e$ original. A Filosofia, como fora dito anteriormente, concederia às questões espirituais rigor e precisão científica assegurada pelo valor dos fatos. Consequentemente, para Bergson (1979b) a metafísica que operasse por meio da inteligência abstrata e conceitual estaria fadada a não representar de modo concreto seu objeto.

O método intuitivo desta forma redirecionaria todo trabalho de investigação da metafísica, trabalhando sobre questões reais a serem pesquisadas, dissolvendo os falsos problemas. A metafísica, assim entendida, deixaria de estudar as ideias e as palavras e estudaria a experiência tal como é de fato vivida, pois como estudar uma ideia que não encontra seu correspondente na realidade concreta? O intelecto isolado da experiência perceptiva fabricaria conceitos $e$ questões irreais, como são as do Nada e Desordem, pois, com efeito, o que seria isso na realidade? (BERGSON, 1979b). Por outro lado a busca de conceitos universais e transcendentais para representar a realidade em geral, acabaria por não abarcar toda multiplicidade, diversidade e riqueza da vida, que o 
homem experimenta. Bergson (1979b), portanto, propôs não o estudo e investigação de ideias abstratas e transcendentais, incompreensíveis à vivência humana, mas o estudo da própria existência, da imanência.

Para Bergson (1979b), a nossa capacidade de criar ideias abstratas e gerais, representações intelectuais ou conceituais, levada a efeito pela Filosofia e Ciência, no final das contas seria fruto de uma função vital que apresentam os seres vivos em geral de selecionar, na diversidade de objetos que os rodeiam, aqueles que possuem características comuns que serviriam às suas necessidades. Considerava que alguns desses objetos prestar-se-iam de fato a representações gerais por apresentarem semelhanças materiais, como ocorre, por exemplo, com certas características que possuem as espécies de seres vivos, com as cores e com os elementos químicos estudados pelo intelecto humano. Entretanto, ao lado das semelhanças que podemos perceber na Natureza, haveria também, como já fora dito anteriormente, uma essência espiritual que dura e que concederia ao Universo a capacidade de agir livre e imprevisivelmente. Reiterava, então, que para esse contato com a realidade espiritual da vida em geral seria necessário o método intuitivo.

O método intuitivo, ao contrário do que os críticos de Bergson pensavam, não seria o instinto, não descartaria a reflexão ou os dados das pesquisas científicas para realizar seus estudos, mas sim os tomaria como base $e$ aprofundaria, atendo-se, entretanto, à duração, ao vivido. Em última análise Bergson (1979d) considerava que as referências a partir das quais seu método desenvolveria suas reflexões seriam compostas pelas intuições realizadas a partir do conjunto das observações e fatos recolhidos pela Ciência e as intuições da própria experiência interna do filósofo, formando o que ele denominou de "experiência integral" (BERGSON, 1979d, p. 39).

\section{As contribuições da duração $e$ da intuição em Bergson para o campo da educação}

Henri Bergson, de acordo com o que esclarece Cesar (1995), não desenvolveu uma teoria da educação e tampouco se dedicou a escrever uma obra 
sobre tal questão. Entretanto identificamos nos textos bergsonianos estudados (mais precisamente em $O$ Pensamento e o Movente - Introdução (segunda parte) e em Intuição Metafísica) algumas reflexões críticas em relação às concepções e métodos pedagógicos recorrentes em sua época, bem como algumas proposições interessantes para a formação do ser humano em um sentido mais amplo. Iremos nos deter mais adiante em algumas considerações acerca destes apontamentos feitos por Bergson. Entretanto, além do que fora diretamente escrito por ele, nos propomos a refletir sobre quais aspectos das considerações feitas acerca da duração e da intuição descritas no capítulo anterior contribuem para repensarmos a educação. Desta forma nos colocamos as seguintes questões: em que medida a concepção de tempo das matemáticas está presente na vida escolar? Como a concepção de duração nos auxiliaria a viver outra lógica na escola? Em que medida seria necessário revermos e questionarmos nosso próprio modo de pensar e entender a construção do conhecimento, compreendendo o alcance e o limite do método da inteligência enraizado em nossa estrutura psicológica, dando, ao mesmo tempo, margem à entrada do método intuitivo no cotidiano escolar? E como, enfim, o desenvolvimento da intuição no contexto da escola nos permitiria reinventar o currículo e modificar nossas práticas pedagógicas?

No período histórico das últimas décadas do século XIX e do começo do século XX (contexto do qual Bergson pôde participar), o pensamento filosófico estava, em grande parte, dominado por tendências positivistas e cientificistas, segundo as quais seriam legítimos apenas os conhecimentos construídos nos moldes das ciências matemáticas, empiricamente observáveis, passíveis de medição e de serem colocados numa cadeia rigorosa, determinista e universal de causa e efeito (PESSANHA, 1979). Santos Pinto (2007) afirma que o paradigma mecanicista de apreensão da natureza, surgido na primeira metade do século XVII, contrapondo-se à concepção antiga e medieval da natureza como um grande organismo vivo e anímico, impôs a necessidade de se estudar os fenômenos de forma generalista, buscando-se alcançar leis científicas universais e imutáveis.

Na segunda metade do século XIX desenvolve-se, então, uma psicologia associacionista, cujos principais representantes, Gustav 
Fechner e Ernst Weber, defendem que o eu psicológico humano é passivel de ser compreendido a partir da associação às leis que regem o funcionamento da matéria. Fechner e Weber buscam, como é tendência nesta época, representar a estrutura dos fenômenos observáveis em leis universais expressas em linguagem matemática, aplicáveis a todos. Eles elaboram, por exemplo, a lei 'segundo a qual qualquer sensação seria diretamente proporcional ao logaritmo de seu estímulo' (SANTOS PINTO, 2007, p. 2).

Vieillard-Baron (2007) acrescenta que tal contexto filosófico e científico estava fortemente vinculado a uma conjuntura política e social mais ampla de desenvolvimento técnico e industrial. Marques (2001) afirma que tais paradigmas da Idade Moderna, com sua busca pela homogeneidade e padronização, caminharam no sentido de criar instituições organizadas com vistas à supressão da heterogeneidade e individualidade humana, atendendo aos interesses econômicos de desenvolvimento. A teoria social, representada pelo pensamento de Augusto Comte, chegava a prever uma ascensão linear e determinista da humanidade (SANTOS PINTO, 2007). Neste sentido, Marques (2001) afirma que a Modernidade acabou por valorizar uma sociedade disciplinar ou normalizadora, repleta de confinamentos para a padronização dos indivíduos. Determinando atitudes e pensamentos uniformizados, o controle passou a ser uma questão de estar "dentro" ou "fora" dos modelos constituídos como normais. Diz Marques (2001) que, durante a criação e organização de instituições na Modernidade, foram tomadas uma série de medidas para se corrigir e controlar as concepções, gestos, atitudes e comportamentos do homem, compreendido então como máquina. Uma das medidas empregadas para tal objetivo foi, ainda de acordo com Marques (2001), o esquadrinhamento do tempo. Tal técnica teria se desenvolvido de modo gradual em escolas como estratégia de treinamento dos sujeitos. As atividades foram divididas em horários pré-determinados, devendo em cada compartimento de tempo ser seguido rigorosa e exclusivamente aquilo que fora previsto, com exclusão de todo elemento perturbador. Estes horários eram, além de pré-determinados, repetidos cíclica e regularmente, em dias, horas, minutos, períodos letivos, anos letivos, bimestres, trimestres, semana de prova, etc. 
Ao lado dessa organização compartimentada e matematizada de tempo, surgem também o programa curricular e o planejamento de aula para serem seguidos à risca. Estes programas foram erguidos, em última análise, por sobre o método da inteligência, que determinava separar o objeto em partes, estudar inicialmente as mais simples e em seguida as mais complexas. Eles prescreviam o que deveria ser feito, o comportamento que deveria ser seguido, em que tempo, a fim de, no final das contas, se alcançarem as metas de produtividade e aprendizado almejadas.

Em outras palavras, os tempos de construção do conhecimento, bem como os métodos de ensino eram padronizados. Os alunos deveriam se adaptar ao processo de aprendizagem proposto de antemão. Neste contexto, a noção de aprendizagem estava circunscrita à ideia de reprodução de um saber, de onde se conclui que o papel do educador era o de transmitir saberes e técnicas já inventadas ou descobertas, repetindo mecanicamente aquilo que the era prescrito.

Cremos, todavia, que houve - $e$ ainda há - um movimento filosófico na educação que tende a valorizar, contrariamente ao modelo acima descrito, a concepção de duração, ao propor uma lógica de trabalho voltada de um lado para a temporalidade dos alunos e de outro para a construção criativa do saber. A filosofia desenvolvida por Henri Bergson pode nos ajudar neste sentido, por ser considerada, conforme acredita Cesar (1995), uma crítica à capacidade do paradigma mecanicista cartesiano e do positivista cientificista de representar de modo completo a realidade. Bergson (1979a) percebeu que a noção de tempo presente nesse paradigma científico-filosófico correspondia a das matemáticas, e que a concepção epistemológica sobre a qual se fundava era restrita. Afirmou que "jamais a medida de tempo se relaciona à duração enquanto tal", que "esta duração, que a ciência elimina, que é difícil de conceber e de exprimir, nós a sentimos e vivemos" (BERGSON, 1979a, p. 102), e por fim que o sujeito possuía na intuição um meio complementar de conhecer "por dentro" o devir.

O pensamento de Bergson nos leva a compreender que não podemos confundir a representação intelectual que criamos do tempo com o tempo em si, a representação intelectual do movimento com o movimento mesmo, em suma, o 
tempo matemático com a duração. O conceito de duração, se bem entendido, nos levaria, em última instância, a vivenciar a realidade da escola sob outra ótica. Não mais apenas o tempo programado, onde todos os eventos estão pré-determinados de modo inflexível em bimestres, semestres, séries, mas também a lógica do devir, do movimento, da imprevisibilidade, da constante reconstrução da realidade e de novos modos de vivê-la. Uma lógica, enfim, que abarcaria também a diferença, que aceitaria e compreenderia a diversidade como algo inerente à vida, trabalhando para desenvolver as potencialidades concretas da duração daqueles sujeitos, estimulando a busca, a curiosidade e a livre iniciativa.

Bergson considerava que a Metafísica em sua origem, com Parmênides e Zenão de Eléia, gerou a busca pelos conceitos universais, pela uniformização da diversidade, apreendendo dela aquilo que supostamente se repete. Marcondes (1998) esclarece que a metafísica, neste contexto, estava interessada em encontrar o Ser das coisas, ou seja, definições abstratas e universais que representariam tudo o que compõem a realidade. Tais definições, ainda de acordo com Marcondes (1998), só seriam alcançadas por um longo exercício de reflexão e opondo-se à experiência concreta, sensivel e imediata que temos das coisas, pois estas não nos levariam às definições imutáveis e universais, mas às opiniões ilusórias, imprecisas e mutáveis. A maior parte dos filósofos se prendeu a essa tendência da metafísica de busca da essência, do conceito absoluto que representaria a diversidade de objetos ou movimentos de um mesmo gênero. Entretanto, quando pensamos na aplicação deste modo de reflexão, por exemplo, na educação, vemos que os ideais universais de organização do trabalho escolar com vistas à uniformização da sociedade, por um lado, não abarcariam a diversidade dos interesses, dos gostos e tendências dos sujeitos da aprendizagem e, por outro, limitaria a criatividade que as durações dos sujeitos poderiam, de modo imprevisível, gerar. A concepção de duração nos traria a compreensão de que o movimento da vida é uma constante criação de possibilidades e realidades, em parte imprevisíveis, que estaríamos constantemente nos esforçando para apreender sem nunca conseguir totalmente. Para Bergson, a vida de um modo geral é livre, cria, faz escolhas, não está pré-determinada. Por que então não poderíamos 
construir uma educação mais aberta, imanente à duração dos sujeitos, que fizesse sentido e fosse construída com base no movimento da vida?

Convém, contudo, destacar que ao lado da duração, em Bergson o conceito de intuição é de grande importância. Santos Pinto (2010) afirma que a filosofia bergsoniana tem em sua base a intuição da duração. $O$ pensador francês acreditava que teoria da vida e teoria do conhecimento estariam intimamente ligados e que, enquanto a estrutura da inteligência estaria mais apta a estudar os fenômenos da vida material, a intuição forneceria o meio mais adequado para o movimento da duração. A experiência intuitiva para Bergson captaria este movimento e proporcionaria o desenvolvimento do aprendizado e, por conseguinte, da evolução. Bergson criticou a ideia defendida por Kant de que seríamos incapazes de perceber e conhecer a duração, ou seja, esta realidade em mudança. Bergson acreditava que a intuição seria um método de pesquisa que deveria ser levado a efeito pela metafísica para conhecer a dinamicidade, a duração da vida, com base em dados conhecidos através da experiência concreta do espírito em relação com o objeto. Entretanto a escola, segundo dizia o próprio Bergson (1979b), apoiava-se em métodos de ensino voltados para formar um ser humano sem o desenvolvimento da reflexão crítica e criatividade. Para ele, o nosso ensino permanecia excessivamente livresco e verbal, expondo o aluno ao contato com dados científicos ou filosóficos prontos e acabados, mas que não passavam pela sua própria experiência de vida e não estimulavam o processo de criação de seu próprio pensamento. Acreditava que em se tratando do estudo das ciências, por exemplo, dever-se-ia expor o aluno à pesquisa concreta, convidandoo a observar, a experimentar, a reinventar, a refletir, para que pudesse por si mesmo perceber a razão e a importância dos conhecimentos e, ao mesmo tempo, se tornasse capaz de criá-los. Embora Henri Bergson tenha valorizado o saber intuitivo não deixou de valorizar a importância da inteligência no processo de criação da ciência e da técnica (BERGSON, 1979b), pois considerava que era próprio do homem de um lado ressignificar a vida e a si mesmo e de outro fabricar objetos. A esse respeito diz Bergson (1979b, p. 148): 
Não vou falar aqui do trabalho manual, da função que ele poderia desempenhar na escola. Somos levados facilmente a ver nele apenas um passatempo. Esquecemos que a inteligência é essencialmente a faculdade de manipular a matéria, que ela ao menos começou assim, que tal era a intenção da natureza. Como então não se beneficiaria a inteligência da educação da mão? [...]. Um saber imediatamente livresco comprime e suprime atividades que querem apenas desenvolver-se.

Mas se a aprendizagem passa necessariamente pela percepção do sujeito cognoscente faz-se mister questionar: que tipo de conteúdo a escola coloca para o aprendizado dos alunos? Será que ele faz parte de suas vivências? Será que pode ser aprofundado pelo estudante? Em que medida pode-se desenvolver a inteligência e a intuição, ampliando o campo de conhecimento do aluno? A escola, neste sentido, seria convidada a ensinar os conteúdos explorando mais o potencial pedagógico das vivências e percepções dos alunos, propondo, ao mesmo tempo, experiências novas e estimulantes para o aprendizado. Contudo, o que geralmente ocorre é a transmissão de textos escritos nos livros didáticos para o aluno decorar, sem que aquilo passe por uma experiência concreta e significativa para o sujeito. Escreve Bergson: "por mais enciclopédico que seja o programa, o que o aluno poderá assimilar da ciência acabada reduzir-se-á a pouca coisa, e será frequentemente estudado sem gosto, e sempre esquecido depressa" (BERGSON, $1979 b$, p. 149). Isso não significa, porém, que todo conhecimento acumulado pela história da humanidade, representado no currículo pela ciência, literatura e arte, deva ser abandonado, mas sim utilizado como base e impulso para que o aluno continue sua busca por saber.

O currículo, na lógica bergsoniana, como expressão mesma da realidade, não deveria estar pronto e acabado, mas em constante reconstrução, aberto, da mesma forma que a vida, a novas buscas e criações. Se a realidade está em constante movimento, por que o currículo deveria estar a priori pronto $e$ acabado? Neste contexto, a escola colocaria professores e alunos na condição de pensadores em meio ao devir, transformá-los-ia em aprendizes frente a uma realidade que é, a cada momento, nova, a qual lhes caberia, em última instância, experimentar, descobrir e criar. 
Para Bergson, a metafísica se distinguiria do modo como a compreendeu Zenão de Eléia, pois o método intuitivo trabalharia sobre questões concretas a serem pesquisadas, e não mais sobre as abstrações. A metafísica, assim entendida, deixaria de estudar as ideias e as palavras e estudaria a existência como de fato se apresenta. Por que não poderia ocorrer o mesmo em relação ao saber escolar? Ao invés de propor questões abstratas para o aprendizado das crianças, a escola ver-se-ia apta a sugerir problemas e dúvidas reais, pertencentes à realidade imediata do aluno. O eminente filósofo parisiense acreditava que a Filosofia teria um potencial muito mais abrangente do que poderíamos pensar (BERGSON, 1979c). Para ele, a Filosofia concederia aos sujeitos uma nova forma de se comportar perante a vida, oportunizando-lhes ir além das camadas mais superficiais do dia-a-dia e adentrar no âmago da vida. Ela extravasaria os ambientes acadêmicos e se converteria em uma atitude perante a realidade, transformar-se-ia em atitude reflexiva diante de si e da realidade externa.

Este modo filosófico bergsoniano de se encarar a vida, a educação e, consequentemente, o currículo, passaria a fazer parte do modo de vida de professores e alunos, renovando a atmosfera do ambiente escolar, transformando o aprendizado em algo mais agradável, porque, de acordo com Bergson (1979c), se de um lado a Ciência pode nos proporcionar bem estar e conforto e Filosofia poderia conceder-nos alegria.

\section{REFERÊNCIAS}

BERGSON, Henri. O Pensamento e o Movente - Introdução (primeira parte). In: BERGSON, Henri. Cartas, conferências e outros escritos. São Paulo: Abril Cultural, 1979a. (Coleção Os Pensadores). p. 99-112

. O Pensamento e o Movente - Introdução (segunda parte). In: BERGSON, Henri. Cartas, conferências e outros escritos. São Paulo: Abril Cultural, 1979b. (Coleção Os Pensadores). p. 113-151

. A intuição filosófica. In: BERGSON, Henri. Cartas, conferências e outros escritos. São Paulo: Abril Cultural, 1979c. (Coleção Os Pensadores) . p. 55-68

Introdução à Metafísica. In: BERGSON, Henri. Cartas, conferências e outros escritos. São Paulo: Abril Cultural, 1979d. (Coleção Os Pensadores). p. 1139 
CESAR, Constança Marcondes. Uma teoria implícita da educação. In: TREVISAN, Rubens Muríllio. Bergson e a educação. Piracicaba: UNIMEP, 1995. p. 13-23

MARQUES, Carlos Alberto. A imagem da alteridade na mídia. 2001. 248f. Tese (Doutorado em Comunicação e Cultura) - Universidade Federal do Rio de Janeiro, Rio de Janeiro, 2001.

MARCONDES, Danilo. Introdução à história da filosofia: dos pré-socráticos a Wittgenstein. Rio de Janeiro: Jorge Zahar, 1998.

MORATO PINTO, Débora; BORBA, Siomara; KOHAN, Walter. Atualidade de Bergson. In: LECERF, Eric; BORBA, Siomara; KOHAN, Walter. Imagens da imanência: escritos em memória de Henri Bergson. Belo Horizonte: Autêntica, 2007. p. $7-25$

PESSANHA, José Américo Motta. Bergson (1859 - 1941): vida e obra. In: BERGSON, Henri. Cartas, conferências e outros escritos. São Paulo: Abril Cultural, 1979. (Coleção Os Pensadores). p. 6-14

SANTOS PINTO, Tarcísio Jorge. Algumas digressões em torno da duração, intuição e educação em Bergson. In: Colóquio Internacional Henri Bergson, 2007, Rio de Janeiro. Anais do Colóquio Internacional Henri Bergson. Rio de Janeiro: UERJ, 2007. p. 1-16.

O método da intuição em Bergson e sua dimensão ética e pedagógica. São Paulo: Loyola, 2010.

VIEILLARD-BARON, Jean-Louis. Compreender Bergson. Petrópolis: Vozes, 2007. 